\title{
Biosemiotics and The Identification of Species- Specific Morphological Characters in The Spider Dysdera Erythrina (Araneae: Dysderidae)
}

Joachim Schult ( $\square$ joachim.schult@uni-hamburg.de)

Universität Hamburg

Onno A. Preik

Universität Hamburg

Stefan Kirschner

Universität Hamburg

Frank Friedrich

Universität Hamburg

\section{Research Article}

Keywords: Dysdera erythrina, spiders, Biosemiotics, specific-mate recognition

Posted Date: August 19th, 2021

DOl: https://doi.org/10.21203/rs.3.rs-787977/v1

License: (1) This work is licensed under a Creative Commons Attribution 4.0 International License. Read Full License 


\section{Abstract}

A biosemiotic approach of interpreting morphological data is apt to reveal morphological traits whose key role in intraspecific communication processes, such as specific mate recognition, has been overlooked so far. Certain genital structures of the haplogyne spider Dysdera erythrina (Walckenaer, 1802) serve as an example. In Dysdera erythrina the semi-circular sclerite at the tip of the male's bulb fits exactly into the anterior diverticulum of the female's endogyne. From the viewpoint of biosemiotics, which studies the production and interpretation of signs and codes in living systems, these structures are considered the morphological zones of an intraspecific communication process which forms one of the necessary prerequisites for sperm transfer and achievement of fertilisation. Thus, a biosemiotics-based species delimitation approach with its peculiar form of evaluation of morphological structures yields new insights for the multidisciplinary undertaking of modern integrative taxonomy.

\section{Introduction}

Biosemiotics studies the production and interpretation of signs and codes in living systems [1] [2]. The modern biosemiotic species concept [2], largely based on Paterson's recognition concept of species [3] [4] [5] [6] [7] [8], lays the focus on those characters, often morphological ones, which serve as signals or signs essential for recognising an appropriate mating partner and achieving fertilisation.

A promising field of applying biosemiotic principles is the genital coupling in spiders with its very complex interactions between the male and female genital structures [9] [10] [11] [12] [13] [14] [15] [16] [17]. As Schult et al. [18] argue, biosemiotically speaking, the fitting between coadapted male and female genital structures can be considered to be a sign whose interpretation leads to or consists of certain effects, such as sperm transfer. Thus, it is not the mechanical fit alone which is important but also the circumstance that the mechanical fit is a sign in the framework of an indispensable communication process. Biosemiotics doesn't stop at asserting functional morphological facts, such as mechanical fits, but goes beyond by asking about their potential meaning in the organism's "subjective world" [19]. It is about understanding communicative processes between organisms, i.e. the meaning of the signs they use, in the context of their particular perceptive environments or "Umwelten", a term coined by Uexküll, which can also be rendered as "self-centred world" or "subjective world" [20]. In a word, biosemiotics studies what organisms may know and what their types and ways of knowing are [21]. As Jackson and Cross [22] conclude in their outstanding and lively description of Portia fimbriata's signals and their reception by potential prey, a human observer at least has to try to interpret spider behaviour from the spider's point of view. Interestingly, although their approach is a biosemiotic one par excellence, Jackson and Cross don't use this term anywhere, which indicates that the principles of biosemiotics are still much too little known in their potential fields of application.

The purpose of our paper is to demonstrate that a biosemiotic approach of interpreting morphological data provides an additional tool to reveal species-specific morphological traits whose key role in intraspecific communication processes and the achievement of fertilisation has been overlooked so far. 
Certain genital structures of the spider Dysdera erythrina (Walckenaer, 1802) will serve as an example. The female and male copulatory organs have always been in the focus of spider taxonomy and species characterization. In what follows we use the term "endogyne" instead of "vulva" to denote the female copulatory apparatus in haplogyne spiders, in analogy to "epigyne" in entelegyne spiders [23] [24] [25]. Despite numerous publications on the genital morphology of spiders the morphological traits of the tip of the male bulb's embolus have commanded only marginal interest up to now. By contrast, a biosemiotic approach reveals that the embolus's tip and its corresponding endogynal structure deserve much more attention with respect to their role in fertilisation and to their taxonomic value.

\section{Results}

The tip of the bulb of Dysdera erythrina is dominated by a semi-circular sclerite (scs) (Fig. 1a-b). Řezáč et al. [26] call it an arch-like ridge. In Fig. $1 \mathrm{~b}$ the exit opening of the ejaculatory duct (ed) is recognisable in a distance of $0.1 \mathrm{~mm}$ from the edge of the semi-circular sclerite.

The dorsal view of the female genitalia (Fig. 1c) reveals the bilobed spermatheca (sp) and the anterior diverticulum (ad). Figure 2 gives information on the course of the genital cavity and the relative position of the spermatheca, the anterior diverticulum (ad) and the posterior diverticulum (pd).

Dysdera erythrina (Fig. 2) possesses a single median genital opening (go), a narrow slit leading anteriorly from the epigastric furrow and opening into the bursa copulatrix (bc). The bursa is lined with a cuticular layer. Ventrally it is much thickened and in parts sclerotised. Posteriorly the bursa dilates into a flexible walled diverticulum (pd). The posterior diverticulum is lined with a thin cuticular layer pierced by chitinous tubercles. Anterodorsally the posterior diverticulum's wall fuses with the entapophysis (e8) (genital 8th somite) (Figs. 1c, 2), a transverse sclerotised bar that forms an important structural support for the endogyne. In addition, the entapophysis forms the dorsal wall of the bursa copulatrix (bc). Anteriorly the bursa ends blindly in a sclerotised diverticulum (ad), which in Dysdera erythrina is clearly pronounced (Figs. 1c, 2). An anterior median ventral passage (mvp) leads from the bursa into the heavily sclerotised bilobed spermatheca.

It is of particular interest and has been unnoticed so far that the anterior diverticulum corresponds in shape and size to the semi-circular sclerite located at the bulb's tip (Fig. 1a-c). Furthermore, the distance between the exit opening of the ejaculatory duct (ed) and the edge of the semi-circular sclerite coincides with the distance between the distal end of the anterior diverticulum and the beginning of the ventralmedian passage leading to the spermatheca (see the bars in Fig. 1a-c). Hence, from the morphological conditions shown in Figs. 1 and 2 it can be inferred that the bulb's distal sclerite is firmly anchored in the anterior diverticulum during copulation. Introducing the bulb's semi-circular sclerite into the anterior diverticulum makes the exit opening of the ejaculatory duct reach the beginning of the duct leading to the spermatheca. This arrangement provides optimal conditions for sperm transmission.

\section{Discussion}


As shown in this paper, there is a striking, hitherto undocumented correspondence between certain morphological structures of the male and female copulatory organs in Dysdera erythrina. The main attention lies on the semi-circular sclerotised structure at the tip of the bulbus, which is arched upwards, and on the centre of this semi-circle where the distal end of the spermophor exits. This structure fits exactly into the anterior diverticulum of the endogyne, with the distal end of the ejaculatory duct reaching the beginning of the duct leading to the spermatheca. Semiotically speaking, this correspondence between the bulb's semi-circular sclerite and the anterior diverticulum is a sign whose interpretation by the male leads to the effect of sperm transfer. From the anchoring of the bulb's tip inside the anterior diverticulum it can be inferred that sperm can only be ejaculated into the anterior diverticulum. The assumption of other authors [27] [28] that sperm is discharged into the posterior diverticulum without reaching the spermathecal lumen and that very likely sperm has to be moved from the posterior diverticulum to the spermathecae after copulation has taken place, cannot be confirmed by the copulation behaviour or the copulation mechanics. Quite the contrary: the fact observed by Uhl [28], that the posterior diverticulum acts as a sperm storage organ, has to be explained by an opposite direction of post-copulatory sperm translocation, namely from the spermathecae to the posterior diverticulum. Considering the endogyne as a whole, only some of its morphological elements can be explained by their function in copulation and sperm collection. Above all, the bow-shaped entapophysis VIII does not seem to be associated with these functions. Its proper functional meaning and semiotic status still have to be identified.

In a biosemiotic context the bulb's semi-circular sclerite and the anterior diverticulum form an intraspecific communication zone during copulation. We suppose that a mechanical mismatch between these structures would constitute a reproductive barrier during copulation, that is, a barrier that operates after mating has begun, but before gametes make contact, as defined by Wojcieszek and Simmons [29]. It is decisive to realise that such a reproductive barrier doesn't exist on the mechanical level alone, but also on the communicative level, as the sign normally produced by the mechanical fit between the bulb's semi-circular sclerite and the anterior diverticulum is now missing. Thus, the intraspecific communication and sign-interpreting processes during copulation as described in Dysdera erythrina can be regarded as necessary prerequisites (among other processes and mechanisms influencing fertilisation success, such as sperm competition and cryptic female choice [30] [31] [32] [33] [34] for successful copulation and sperm transfer. It is highly probable that the underlying morphological traits are species-specific. The shape of the distal semi-circular sclerite of the male bulb in Dysdera erythrina is completely different from the way in which the distal end of the male bulb of other Dysdera species, even very closely related ones, is formed [24] [26] [35] [36] [37] [38] [39]. However, further comparative studies are needed for a final determination of the taxonomic status of these structures.

The physiological basis of the intraspecific communication and sign-interpreting processes as described above is still unknown. Interestingly, in the entelegyne spider Philodromus cespitum it has recently been shown that the bulb, commonly considered a numb organ [40], possesses neural tissue and a multisensillar sensory organ situated close to the base of the embolus [41]. Furthermore, neurons are associated with two glands within the bulbus, the fundus gland and the embolus gland. Sentenská et al. 
[41] suggest that the "sperm expulsion may be triggered when the sensory organ sends information about the correct positioning of the pedipalp during mating. This afferent transmission may cause the fundus gland to release the substance from its reservoir into the spermophor lumen to flush out the seminal fluid stored therein." Pioneer work in this area was done by Lipke et al. [42] who for the first time documented the presence of neurons and a nerve inside the palpal bulb of a spider, the haplogyne Tasmanian cave spider Hickmania troglodytes. As „the arrangement of the nerve and neurons in $H$. troglodytes and $P$. cespitum is nearly identical although the bulbi differ considerably between these two species", which belong to distantly related taxa, Sentenská et al. [41] assume "that the presence and arrangement of the neural tissue represents a ground pattern for all Araneomorphae and possibly for all spiders." Their assumption was impressively confirmed by Dederichs et al. [43] corroborating that in another nine spider taxa there is a bulb nerve, which is a distal branch of the palpal nerve. Moreover, Dederichs et al. [43] found afferent or efferent neurite bundles projecting from the bulb nerve into various parts of the palpal organ, a sensory organ at the base of the embolus in several of the investigated taxa and nervous tissue close to the glandular tissue of the spermophor. Future research has to clarify, whether the bulb of Dysdera erythrina is also innervated. If so, an explanation would be at hand of how the mechanical fit between the bulb's semi-circular sclerite and the anterior diverticulum, which serves as a sign that the embolus and its exit opening of the ejaculatory duct have reached their correct position for sperm transfer, is perceived.

As exemplified by Dysdera erythrina, a biosemiotic shift from the purely morphological to the communication and information aspect by strictly focussing only on those morphological structures that are essential for intraspecific communication is apt to avoid typological interpretations of morphological structures and the problems usually associated with them [18] [44].

For a long time, taxonomy in spiders has almost exclusively depended on morphological characters, mostly focussing on the male secondary copulatory organ (palpal bulb) and the female reproductive organ. Almost the entire literature on Dysdera erythrina - for example Charitonov et. al. [45] (22, Fig. 1), Cooke [27], Drensky [46] (91, Fig. 8e), Dresco [47] (248, Fig. 2), Harvey [48], Heimer \& Nentwig [49] (44), Kovblyuk et al. [50], Locket \& Millidge [51] (85, Fig. 42A), Muller [52], Řezáč, et al. [26], Simon [53] (97, Fig. 168), Uhl [28] (164, Fig. 1), Wiehle [54] (17, Figs. 40, 42) - usually contains only very superficial representations of the bulbs and vulvae or endogynes. Even in the more detailed images of the bulbs and endogynes of Dysdera erythrina offered by Blackwall [55] (pl. XXVIII, Fig. 266f), Grasshoff [56], Schult [57], Roberts [58] [59] and others the structures are not related to one another. In summary, the complexity of these structures and their communicative meaning have not been taken into account.

The publications by Arnedo \& Ribera [24] [35] and Arnedo et al. [36] [37] contain relatively accurate drawings of the bulb and the endogyne as well as REM photos of the bulb tips of various Dysdera species. However, a possible complementarity between the bulb's tip and structures of the endogyne is not examined here either. Macías-Hernández et al. [38] have shown how DNA sequence data, together with morphometric, distributional and ecological information assists in identifying and diagnosing previously overlooked lineages. They present SEM photos of the tips of the bulbs and very precise 
drawings of the endogynes of different Dysdera species, but they don't treat a possible complementarity between these structures. The same is true of Crespo et al. [39], who have described eight new Dysdera species from the Madeira archipelago based on the integration of morphological and molecular data.

Uhl [28] provides a semi-diagrammatic drawing of a longitudinal section of the female genitalia of Dysdera erythrina that is doubtless absolutely correct. However, it does not demonstrate the meaning of this structure in its functional context, as Uhl's figures do not sufficiently illustrate aspects and parts that are decisive for successful sperm transmission. With the section plane as chosen by Uhl neither the exact correspondence between the anterior diverticulum and the distal semi-circular sclerite of the male bulb can be seen, nor is the anterior median ventral passage leading from the bursa into the heavily sclerotised bilobed spermatheca recognisable. Consequently, the functional aspect of the female genitalia of Dysdera erythrina has been widely neglected.

Particularly noteworthy is the study of Řezáč et al. [26], in which in addition to morphological structures, karyotype and DNA sequences are used to distinguish the species within the Dysdera erythrina speciescomplex. Řezáč et al. [26] identify the teeth-like structures on the anterior side of the lateral tips of the spermatheca in Dysdera erythrina as a species character and interpret them as muscle anchors. Furthermore, they state that Dysdera erythrina differs from the other species in that the male bulb has an almost apically positioned, straight, triangle-shaped posterior apophysis with a tooth on its proximal side. From a biosemiotic point of view the question arises of what role these postulated species-specific characters might play in communication processes between the sexes. Moreover, it might be asked whether it is justified to consider these structures as species-specific characters at all if no such communicative function can be made plausible. We do not want to downplay the importance of the results provided by Řezáč et al. [26], but we are convinced that a biosemiotics-based species delimitation approach as a complementary method can offer new insights or corroborate results achieved through other methods.

In one of his numerous studies on genital mechanics and copulatory mechanisms in Pholcids [12] [13] [14] [15] [60] [61] [62] [63] [64] [65] Huber has already proposed the idea that the female might perceive the mechanical fit of those structures of the male copulatory organ that have contact [12]. Regrettably, Huber's line of thought, which has a lot in common with a biosemiotic point of view [18], has not been seriously pursued by others. As Eberhard \& Huber [40] (255) state, "most studies of the functional anatomy of [spider] genitalia are unfortunately extremely typological".

The sclerites of the genital bulb are considered to be fused. As a basis for phylogenetic interpretations, Kraus [66] presents a detailed account of the morphological features of the different forms of male palpal organs with special consideration of those structural elements that are complementary to the epigynal area. Agnarsson et al. [67] have reviewed the morphology of the male palpal organ in the spider family Theridiidae by applying a topological method that identifies homologous sclerites by means of their relative position. The bulb is a very complex system within which the cooperation between sclerites 
and inflatable areas (haematodochae) is very important [68]. Also, the complicated torsion of the bulbs before copulation is not understandable without a description of their morphological characteristics.

Usually, the bulb has not been considered in context and as part of a specific biological communication system. This is in stark contrast to statements such as Laubichler's [69] (417), stressing: "What is perhaps the most striking feature of biological processes in general is the functionality or their meaningfulness". Huber [70] points out the pivotal role of studies by Eberhard and West-Eberhard [71] [72] [73] in demonstrating that copulatory organs are also courtship organs and "competitive signalling devices" [72].

Concerning the evolution of the complex male and female genital structures in spiders, biosemiotics might add a new aspect to Eberhard and Huber's model of rapid evolutionary divergence due to sexual selection by cryptic female choice. Eberhard \& Huber [40] (263-264) postulate: "Seen from the evolutionary perspective of females, the mechanical problems experienced by males that lack sense organs in their genitalia could lead to selection on females to discriminate against those males least able to achieve effective genitalic alignment, either through the stimuli received or via changes in morphology that bias male abilities to fit mechanically. The female could gain via the production of sons with superior genitalic designs. [...] The female would thus be exercising sexual selection by cryptic female choice with respect to the male's ability to adjust mechanically to her complex genitalic morphology."

With the recent findings of innervation in the bulbs of several spider species (see above) Eberhard's and Huber's model seems all the more plausible. Seen from a biosemiotic perspective the male's ability to achieve effective genitalic alignment or to adjust mechanically to the female's genitalic morphology depends on the male's general ability to adequately interpret signs and to perform semiotic processes, i.e. it depends on its cognitive ability, which is defined as the potential to acquire, retain, process and use information to adjust behavior [74] [75]. A biosemiotic approach goes beyond any common functional morphological analysis of spider genitalia. We hypothesize that in spiders, sexual selection by cryptic female choice leads to a general improvement of male cognitive ability, which in turn increases the male's ability to survive and reproduce. So far experimental studies on the effect of mate system variation on the evolution of cognition in invertebrates are very rare. Hollis et al. [76] have experimentally shown that in Drosophila melanogaster sexual selection leads to a general improvement of male cognitive ability, which was tested by a task implying associative learning. Males stemming from populations that had been raised for over 100 generations under strict monogamous conditions excluding mate choice and competition for mates revealed reduced ability to avoid an odour previously paired with aversive shock when compared to polygamous males. On the other hand, experimental evolution in seed beetles has shown that sexual selection increased males' performance in cognitively demanding mate search, but it did not lead to general increases in their cognitive abilities [77]. Of course, only future experiments with spiders can prove or refute our hypothesis.

It is quite clear that a successful sperm transfer requires the correct position of the embolus and the exit opening of its ejaculatory duct. Furthermore, for the sperm transfer to be initiated there must be some 
signal that the correct position of the embolus has been achieved. Obviously, the mechanical fitting together of the embolus and a corresponding female genital structure is the best candidate for providing such a sign. In Argiope bruennichi, judging by the shape of the sperm transferring part (e1 in Fig. 4D in Uhl et al. [17]) of the embolus, this seems to be the case when this part of the embolus lies completely against the inner wall of the atrium, an aspect that until now hasn't received the attention it deserves.

The copulation behaviour of Dysdera erythrina has already been sufficiently described by previous authors [78] [79]. The insertion of the bulbs is simultaneous; the male pushes the tip of the left bulb into the right half and the tip of the right bulb into the left half of the female bursa copulatrix. However, it has been overlooked by other authors that one embolus intrudes a little deeper than the other and that shortly thereafter the bulbs change their position, i.e. the deeper inserted embolus is retracted while the other embolus is slightly pushed forward (unpublished observation by J. Schult on May 14, 1984). This behaviour could be explained if we assume that the morphological conditions allow only one distal sclerite of the bulb being inserted into the anterior diverticulum at a time.

The morphological conditions shown in Figs. 1 and 2 clearly indicate that in Dysdera erythrina the bulb's distal sclerite is anchored in the anterior diverticulum during copulation. The hypothesis of an adaptation between these special parts of the bulb and the endogyne has been verified by microscopic examination and by means of SEM photographs. In the framework of biosemiotics, the bulb's distal sclerite and, perfectly fitting to it in shape and size, the anterior diverticulum are considered morphological zones of an intraspecific communication and sign-interpreting process that is one of the necessary prerequisites for sperm transfer. Hence these morphological elements deserve particular attention, as they are of higher taxonomic value than those morphological traits of the bulb for which a relevant role in mating and fertilisation has not been proven. In our view it is an oversimplification by Quade et al. [68] to state that, because "the bulb of a male spider fits only into the genital opening of a female of the same species, [...] the shape of all bulb components is species specific".

As is well-known, in addition to morphological structures there are a number of other factors, such as behaviour [22] [33], pheromones [80], habitat, courtship periods, etc., which either prevent mating between species or enhance specific mate recognition and the achievement of fertilisation. Therefore, even with compatible morphological structures, a reproductive community cannot be assumed for sure, as is the case with the "ethospecies" Schizocosa ocreata (Hentz) and S. rovneri (Uetz and Dondale) [81]. However, if structures fail to match, which are necessary for communication processes involved in the recognition of an appropriate mating partner and the achievement of fertilisation, reproductive isolation follows per definitionem. In our view a biosemiotic approach clearly helps to identify the relevant structures.

Thus, a special emphasis on structures that hold semiotic meaning would enhance the purely comparative approach of morphological species classification. If we direct our attention to structures that possess a communicative function, structural comparison and decisions based on differences or similarities in this area would provide additional clues for species delimitation. Theoretically, strong emphasis on divergence in key structures might even de-cluster very similar species. Cases in which 
comparative morphology of genitalia unexpectedly turned out to be useless for recognising reproductive units [82] might be seen in a new light if biosemiotic principles are applied. Especially when behavioural or physiological traits are unavailable, decision processes would benefit from a biosemiotics-based species delimitation approach as a new source of data within the multidisciplinary undertaking of modern integrative taxonomy [83] [84].

\section{Materials And Methods}

\section{Material examined}

Dysdera erythrina (Walckenaer, 1802): 2 female adults (Fig. 1C), collected by Joachim Schult in Freiburg i. $\mathrm{Br}$. (Germany) in 1997. They were determined by J. Schult and deposited in the Museum of Nature and Environment (Lübeck, Germany). 1 male adult (Fig. 1a-b) from the Centrum für Naturkunde (CeNak, Hamburg, Germany), collected by W. Bösenberg and determined by him in 1900 (list no. 814). 1 female adult (Fig. 2), collected by Stefan Lauterbach in Bestwig (Sauerland, Germany) in 2018 and determined by him. This specimen is deposited in the Institute of Zoology of the University of Hamburg.

\section{Specimen preparation and imaging}

For morphological investigation male pedipalps of Dysdera erythrina were isolated, embedded in Hoyer's medium [85], and investigated light microscopically using a Leitz Stereomicroscope and a Leitz Orthoplan with interference contrast.

Morphological investigation of the longitudinal sections of the female genitalia of Dysdera erythrina stained with aniline blue and nuclear fast red staining was carried out with a Leica M2 16/ Camera Leica DFC 320/ Leica Application Suite 4.6.0. For scanning electron microscopy the male parts of Dysdera erythrina were fixed in $70 \%$ ethanol, dehydrated in serial dilutions of ethanol, transferred in acetone, critical point dried (Leica CPD 300), and coated with carbon (Leica ACE 600). The preparations were embedded in Hoyer's mixture [86] between two coverslips and investigated in a Zeiss LEO 1525 scanning electron microscope (SEM). Furthermore, a SEM photograph made by J. Schult in 1983 has been reinterpreted based on a biosemiotic approach (Fig. 1c). While this older photo does not meet current standards in every respect, the structures in question are clearly visible. The SEM (Stereoscan S4, Cambridge Scientific Instruments, Ltd.) was a loan from the DFG (Deutsche Forschungsgemeinschaft, German Research Foundation) to the former working group "Hard Body Morphology" at the Institute of Zoology, University of Hamburg.

\section{Declarations}

\section{Compliance with ethical standards}

We neither used endangered species nor were the investigated animals collected in protected areas. All applicable international, national, and/or institutional guidelines for the care and use of animals were 
followed. This article does not contain any studies with human participants performed by any of the authors.

\section{Data Availability}

The datasets generated and analysed during the current study are available from the corresponding author on reasonable request.

\section{Acknowledgements}

This study was supported by a grant from the University of Hamburg. Specimens were kindly provided by Dr. Hubert Höfer (Naturkundemuseum Karlsruhe, Germany), Dr. Danilo Harms and Nadine Dupérré (CeNak, Hamburg, Germany), Stefan Lauterbach (Essen, Germany) and Dr. Alexander Sührig (Göttingen, Germany). We also extend our thanks to Renate Walter (Zoological Institute of the University of Hamburg) who operated the scanning electron microscope.

Furthermore, we are most grateful to Annett Röper-Steinhauer PhD (Leuphana University Lüneburg), Dr. W. Hinners and Prof. Dr. Lisa Kirch for carefully reading a previous draft and checking the content and language. Our thanks also go to Dr. Susanne Füting (Museum für Natur und Umwelt, Lübeck) for references and Dr. Philipp Schult (University of Bonn) for helping us with image processing.

\section{Author Contributions}

J.S. conceived the study. J.S. and O.A.P. performed the microscopy, F.F. participated in the SEM work. J.S., O.A.P. and S.K. wrote the manuscript. All authors read and approved the final manuscript.

Competing Interests: The authors declare no competing interests.

\section{References}

1. Favareau, D. Essential readings in biosemiotics. Anthology and commentary (Springer, 2010).

2. Kull, K. The biosemiotic concept of the species. Biosemiotics 9, 61-71 (2016).

3. Paterson, H. The recognition concept of species in Species and speciation (ed. Vrba, E. S.) 21-29 (Transvaal Museum, Pretoria, 1985).

4. Paterson, H. On defining species in terms of sterility: problems and alternatives. Pacific Science $\mathbf{4 2}$, 65-71 (1988).

5. Masters, J. C. et al. The concept of species: recognition versus isolation. S. Afr. J. Sci. 83, 534-537 (1987).

6. Lambert, D. M. \& Spencer, H. G. (eds). Speciation and the recognition concept: theory and application (Johns Hopkins University Press, 1995).

7. Stamos, D. N. The species problem. Biological species, ontology, and the metaphysics of Biology (Lexington Books, 2003), 197-199. 
8. Mallet, J. Species, concepts of in Encyclopedia of Biodiversity, Vol. 6 (ed. Levin, S. A.) 679-691 (Elsevier, 2013), 682-683.

9. Grasshoff, M. Morphologische Kriterien als Ausdruck von Artgrenzen bei Radnetzspinnen der Subfamilie Araneinae (Arachnida: Araneae: Araneidae). Abh. Senckenberg Naturforsch. Ges. 516, 1100 (1968).

10. Grasshoff, M. Bau und Mechanik der Kopulationsorgane der Radnetzspinne Mangora acalypha (Arachnida, Araneae). Z. Morph. Tiere 74(3), 241-252 (1973a).

11. Grasshoff, M. Konstruktions- und Funktionsanalyse an Kopulationsorganen einiger Radnetzspinnen. Aufsätze und Reden der Senckenbergischen Naturforschenden Gesellschaft 24, 129-151 (1973b).

12. Huber, B. A. Genital mechanics and sexual selection in the spider Nesticus cellulanus (Araneae: Nesticidae). Can. J. Zool. 71, 2437-2447 (1993).

13. Huber, B. A. Genital morphology, copulatory mechanism and reproductive biology in Psilochorus simoni (Berland, 1911) (Pholcidae; Araneae). Neth. J. Zool. 44(1-2), 85-99 (1994a).

14. Huber, B. A. Copulatory mechanics in the funnel-web spiders Histopona torpida and Textrix denticulata (Agelenidae, Araneae). Acta Zool. (Stockholm) 75(4), 379-384 (1994b).

15. Huber, B. A. Genital mechanics in some neotropical pholcid spiders (Araneae: Pholcidae), with implications for systematics. J. Zool., Lond. 244, 587-599 (1998).

16. Uhl, G., Huber, B. A. \& Rose, W. Male pedipalp morphology and copulatory mechanism in Pholcus phalangioides (Fuesslin, 1775) (Araneae, Pholcidae). Bull. Br. Arachnol. Soc. 10(1), 1-9 (1995).

17. Uhl, G.; Nessler, S. H. \& Schneider, J. Copulatory mechanism in a sexually cannibalistic spider with genital mutilation (Araneae: Araneidae: Argiope bruennichi). Zoology 110, 398-408 (2007).

18. Schult, J., Preik, O. \& Kirschner, S. The importance of biosemiotics for morphology. Biosemiotics 14/1, 167-179 (2021).

19. Barbieri, M. A short history of biosemiotics. Biosemiotics 2, 221-245 (2009).

20. Kull, K. Jakob von Uexküll: An introduction. Semiotica 134(1/4), 1-59 (2001).

21. Kull, K. Advancements in biosemiotics: Where we are now in discovering the basic mechanisms of meaning-making in Gatherings in Biosemiotics (eds. Rattasepp, S. \& Bennett, T.) 11-24 (University of Tartu Press, 2012).

22. Jackson, R. \& Cross, F. R. Spider cognition in Spider physiology and behaviour: Behaviour (ed. Casas, J.) 115-174 (Elsevier/Academic Press, 2011).

23. Mkheidze, T. S. New species of spiders of the genus Harpactocrates (Dysderidae) in Georgia. Soobshcheniia Akademii Nauk Gruzinskoi SSR 68, 741-744 (1972).

24. Arnedo, M. \& Ribera, C. Radiation of the genus Dysdera (Araneae, Haplogynae, Dysderidae) in the Canary Islands: The island of Gran Canaria. Zoologica Scripta 26(3), 205-243 (1997).

25. Fomichev, A. A. \& Marusik, Y. M. Notes on the spider genus Segestria Latreille, 1804 (Araneae: Segestriidae) in the East Palaearctic with description of three new species. Zootaxa 4758(2), 330346 (2020). 
26. Řezáč, M., Arnedo, M. A., Opatova, V., Musilová, J., Řezáčová, V. \& Král, J. Taxonomic revision and insights into the speciation mode of the spider Dysdera erythrina species-complex (Araneae: Dysderidae): sibling species with sympatric distributions. Invertebr. Syst. 32, 10-54 (2018).

27. Cooke, J. A. L. Synopsis of the structure and function of the genitalia in Dysdera crocata (Araneae, Dysderidae). Senckenbergiana Biologica 47, 35-43 (1966).

28. Uhl, G. Two distinctly different sperm storage organs in female Dysdera erythrina (Araneae: Dysderidae). Arthropod Struct. Dev. 29, 163-169 (2000).

29. Wojcieszek, J. M. \& Simmons, L. W. Divergence in genital morphology may contribute to mechanical reproductive isolation in a millipede. Ecol. Evol. 3(2), 334-343 (2013).

30. Eberhard, W. G. Why study spider sex: Special traits of spiders facilitate studies of sperm competition and cryptic female choice. J. Arachnol. 32, 545-556 (2004).

31. Firman, R. C., Gasparini, C., Manier, M. K. \& Pizzari, T. Postmating female control: 20 years of cryptic female choice. Trends Ecol. Evol. 32(5), 368-382 (2017).

32. Herberstein, M. E., Schneider, J. M., Uhl, G. \& Michalik, P. Sperm dynamics in spiders. Behav. Ecol. 22(4), 692-695 (2011).

33. Schneider, J. \& Andrade, M. Mating behaviour and sexual selection in Spider behaviour: flexibility and versatility (ed. Marie Elisabeth Herberstein, M. E.) 215-274 (Cambridge Univ. Press, 2011).

34. Uhl, G. \& Vollrath, F. Genital morphology of Nephila edulis: implications for sperm competition in spiders. Can. J. Zool. 76(1), 39-47 (1998).

35. Arnedo, M. \& Ribera, C. Radiation of the genus Dysdera (Araneae, Dysderidae) in the Canary Islands: The island of Tenerife. J. Arachnol. 27, 604-662 (1999).

36. Arnedo, M., Oromi, P., Múrria, C., Macías-Hernández, N. \& Ribera, C. The dark side of an island radiation: systematics and evolution of troglobitic spiders of the genus Dysdera Latreille (Araneae: Dysderidae) in the Canary Islands. Invertebrate Systematics 21(6), 623-660 (2007).

37. Arnedo, M., Gasparo, F. \& Opatova, V. Systematics and phylogeography of the Dysdera erythrina species complex (Araneae, Dysderidae) in Sardinia. ZooKeys 16, 319-345 (2009).

38. Macías-Hernández, N., Oromí, P. \& Arnedo, M. Integrative taxonomy uncovers hidden species diversity in woodlouse hunter spiders (Araneae, Dysderidae) endemic to the Macaronesian archipelagos. Syst. Biodivers. 8, 531-553 (2010).

39. Crespo, L. C., Silva, I., Enguídanosi, A., Cardoso, P. \& Arnedo, M. A. Integrative taxonomic revision of the woodlouse-hunter spider genus Dysdera (Araneae: Dysderidae) in the Madeira archipelago with notes on its conservation status. Zool. J. Linn. Soc. XX, 1-60 (2020).

40. Eberhard, W. G. \& Huber, B. A. Spider genitalia. Precise maneuvers with a numb structure in a complex lock in The evolution of primary sexual characters in animals (eds. Leonard, J. L. \& Córdoba-Aguilar, A.) 249-284 (Oxford University Press, 2010).

41. Sentenská, L., Müller, C. H. G., Pekár, S. \& Uhl, G. Neurons and a sensory organ in the pedipalps of male spiders reveal that it is not a numb structure. Scientific Reports 7, 12209; DOI:10.1038/s41598- 
017-12555-5 (2017).

42. Lipke, E., Hammel, J. U. \& Michalik, P. First evidence of neurons in the male copulatory organ of a spider (Arachnida, Araneae). Biol. Lett. 11, 20150465, http://dx.doi.org/10.1098/rsbl.2015.0465 (2015).

43. Dederichs, T. M., Müller, C. H. G., Sentenská, L., Lipke, E., Uhl, G. \& Michalik, P. The innervation of the male copulatory organ of spiders (Araneae) - a comparative analysis. Front Zool 16, 39; https://doi.org/10.1186/s12983-019-0337-6 (2019).

44. Schult, J. Morphologische Merkmale als Zeichen in Biosemiotik - praktische Anwendung und Konsequenzen für die Einzelwissenschaften (ed. Schult, J.) 101-119 (VWB, 2004).

45. Charitonov, D. E. Obzor paukov semeistva Dysderidae fauny SSSR. Uchenye Zapiski olotovskogo Gosudarstvennogo Universiteta Imeni A. M. Gor'kogo 10, 17-39 (1956).

46. Drensky, P. Faounata na paiatzite (Araneae) w Beulgaria. II. Podrazred Arachnomorphae; I klon Tetrastica; semeystwa Filistatidae; Dysderidae i Oonopidae. Izvestiya na Tsarskite Prirodonauchni Instituti v Sofia 11, 81-106 (1938).

47. Dresco, E. Araignées de Bretagne. Le genre Dysdera (fam. Dysderidae). Bulletin de la Société Scientifique de Bretagne 47, 245-256 (1972).

48. Harvey, P. Identification of Dysdera crocata and Dysdera erythrina. Newsletter of the British Arachnological Society 114, 17 (2009).

49. Heimer, S. \& Nentwig, W. Spinnen Mitteleuropas: Ein Bestimmungsbuch. (Paul Parey, 1991).

50. Kovblyuk, M. M., Prokopenko, E. V. \& Nadolny, A. A. Spider family Dysderidae of the Ukraine (Arachnida, Aranei). Euroasian Entomological Journal 7(4), 287-306 (2008).

51. Locket, G. H. \& Millidge, A. F. British spiders, Vol. I (Ray Society, 1951).

52. Muller, L. Les haplogynes dans le Grand-Duché de Luxembourg. Archives de I'Institut Grand-Ducal de Luxembourg 32, 117-127 (1967).

53. Simon, E. Les arachnides de France. Synopsis générale et catalogue des espèces françaises de I'ordre des Araneae. Tome VI. $1^{\text {re }}$ partie (Roret, 1914).

54. Wiehle, H. Spinnentiere oder Arachnoidea (Araneae) IX: Orthognatha-Cribellatae-HaplogynaeEntelegynae (Pholcidae, Zodariidae, Oxyopidae, Mimetidae, Nesticidae). Die Tierwelt Deutschlands 42, 1-150 (1953).

55. Blackwall, J. A history of the spiders of Great Britain and Ireland. Part II. (London: Ray Society, 1864). PI. XXVIII, fig. 266.

56. Grasshoff, M. Dysdera-Arten von Inseln der Mittelmeergebietes (Arach., Araneae). Senckenbergiana Biologica 40(3/4), 209-220 (1959).

57. Schult, J. Taster haplogyner Spinnen unter phylogenetischem Aspekt (Arachnida: Araneae). Verh. Naturwiss. Ver. Hamb. 26, 69-84 (1983).

58. Roberts, M. J. The spiders of Great Britain and Ireland, Volume 1: Atypidae to Theridiosomatidae (Harley Books, 1985). 
59. Roberts, M. J. Spinnengids (Tirion, 1998).

60. Huber, B. A. Copulatory mechanism in Holocnemus pluchei and Pholcus opilionoides, with notes on male cheliceral apophyses and stridulatory organs in Pholcidae (Araneae). Acta Zool. (Stockholm) 76(4), 291-300 (1995a).

61. Huber, B. A. Genital morphology and copulatory mechanics in Anyphaena accentuata (Anyphaenidae) and Clubiona pallidula (Clubionidae: Araneae). Journal of Zoology, London 235, 689-702 (1995b).

62. Huber, B. A. On American 'Micromerys' and Metagonia (Araneae, Pholcidae), with notes on natural history and genital mechanics. Zoologica Scripta 25(4), 341-363 (1997).

63. Huber, B. A. Sexual selection in pholcid spiders (Araneae, Pholcidae): Artful chelicerae and forceful genitalia. J. Arachnol. 27, 135-141 (1999).

64. Huber, B. A. Functional morphology of the genitalia in the spider Spermophora senoculata (Pholcidae, Araneae). Zool. Anz. 241, 105-116 (2002).

65. Huber, B. A. \& Eberhard, W. G. Courtship, copulation, and genital mechanics in Physocyclus globosus (Araneae, Pholcidae). Can. J. Zool. 74, 905-918 (1997).

66. Kraus, O. Male spider genitalia: evolutionary changes in structure and function. Verh. Naturwiss. Ver. Hamb. (NF) 27, 373-382 (1984a).

67. Agnarsson, I., Coddington, J. A. \& Knoflach, B. Morphology and evolution of cobweb spider male genitalia (Araneae, Theridiidae). J. Arachnol. 35, 334-395 (2007).

68. Quade, F. S. C., Holtzheimer, J., Frohn, J., Töpperwien, M., Salditt, T. \& Prpic, N.-M. Formation and development of the male copulatory organ in the spider Parasteatoda tepidariorum involves a metamorphosis-like process. Scientific Reports 9, 6945; https://doi.org/10.1038/s41598-019-43192-9 (2019).

69. Laubichler, M. D. A semiotic perspective on biological objects and biological functions. Semiotica 127, 415-431 (1999).

70. Huber, B. A. The significance of copulatory structures in spider systematics in Biosemiotik praktische Anwendung und Konsequenzen für die Einzelwissenschaften (ed. Schult, J.) 89-100 (VWB, 2004).

71. Eberhard, W. G. Sexual selection and animal genitalia. (Harvard Univ. Press, 1985).

72. West-Eberhard, M. J. Sexual selection, competitive communication and species-specific signals in insects in Insect communication (ed. Lewis, T.) 283-324 (Academic Press, 1984).

73. West-Eberhard, M. J. Sexual selection, social competition, and speciation. Quart. Rev. Biol. 58(2), 155-183 (1983).

74. Dukas, R. Evolutionary biology of animal cognition. Annu. Rev. Ecol. Evol. Syst. 35, 347-374 (2004).

75. Shettleworth, S. J. (2010). Cognition, evolution, and behavior (Oxford University Press, 2010).

76. Hollis, B. \& Kawecki, T. J. Male cognitive performance declines in the absence of sexual selection. Proc. R. Soc. B 281, 20132873, http://dx.doi.org/10.1098/rspb.2013.2873 (2014). 
77. Baur, J., d'Amour Nsanzimana, J. \& Berger, D. Sexual selection and the evolution of male and female cognition: A test using experimental evolution in seed beetles. Evolution 73(12), 2390-2400 (2019).

78. Cooke, J. A. L. Spider genus Dysdera (Araneae, Dysderidae). Nature 205, 1027-1028 (1965).

79. Helversen, O. Gedanken zur Evolution der Paarungsstellung bei den Spinnen (Arachnida: Araneae). Entomol. Germ. 3, 13-28 (1976).

80. Gaskett, A. C. Spider sex pheromones: emission, reception, structures, and functions. Biol. Rev. 82, 27-48. (2007).

81. Roberts, J. A. \& Uetz, G. W. Chemical signaling in a wolf spider: A test of ethospecies discrimination. J. Chem. Ecol. 30(6), 1271-1284 (2004).

82. Tanabe, T., Katakura, H. \& Mawatar, S. F. Morphological difference and reproductive isolation: morphometrics in the millipede Parafontaria tonominea and its allied forms. Biol. J. Linn. Soc. 72, 249-264 (2001).

83. Dayrat, B. Towards integrative taxonomy. Biol. J. Linn. Soc. 85, 407-415 (2005).

84. Řezáč, M., Gasparo, F., Král, J. \& Heneberg, P. Integrative taxonomy and evolutionary history of a newly revealed spider Dysdera ninnii complex (Araneae: Dysderidae). Zool. J. Linn. Soc. 172, 451474 (2014).

85. Kraus, O. Hoyers Gemisch statt Polyvinyl-Lactophenol. Mikrokosmos 73, 54- 55 (1984b).

86. Crabill, R. E. A new Schendylid from the Eastern United States, with notes on distribution and morphology. (Chilopoda: Geophilomorpha: Schendylidae). Ent. News 69(6), 153-160 (1958).

\section{Figures}



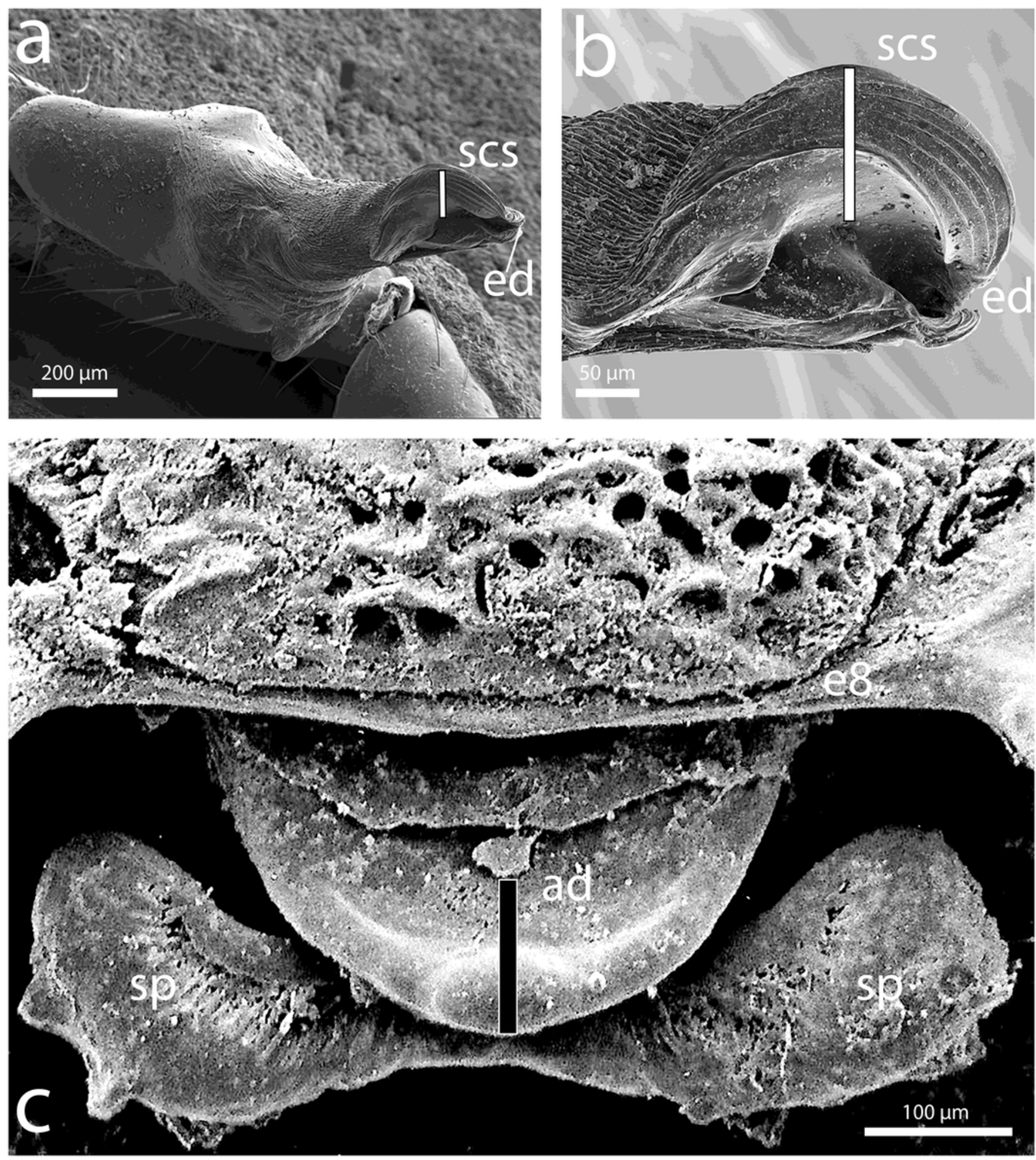

Figure 1

Dysdera erythrina, male pedipalp, bulb and female genitalia, bars (length corresponds to $100 \mu \mathrm{m}$ ) indicating the spatial correspondence between the semi-circular sclerite (scs) and the anterior diverticulum (ad). (a, b) scs, semi-circular sclerite at the tip of the bulb; ed, ejaculatory duct. (c) ad, anterior diverticulum of the endogyne; sp, spermatheca; e8, entapophysis. 


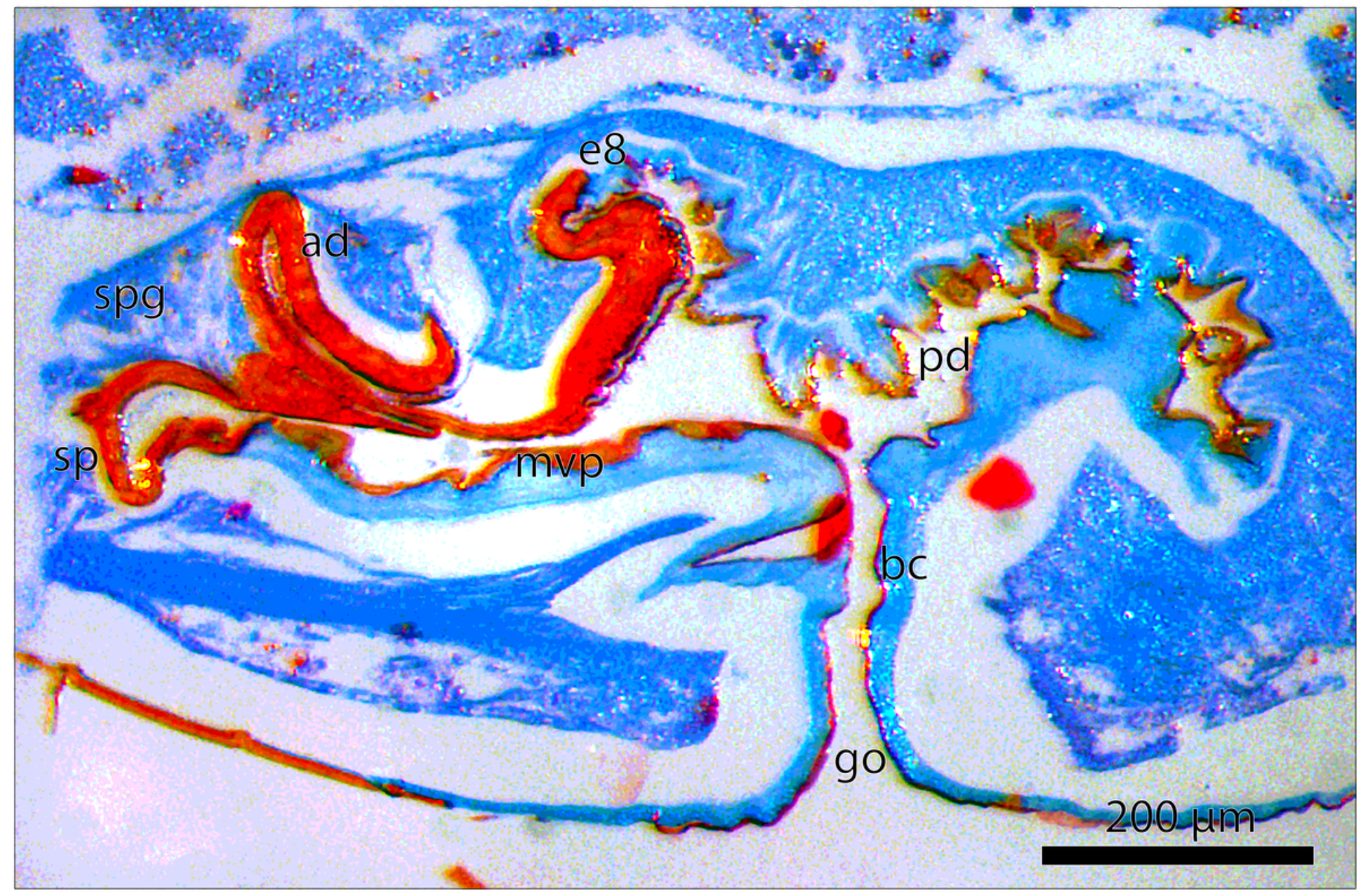

Figure 2

Median longitudinal section through the female genitalia of Dysdera erythrina. Abbreviations: go, genital opening; bc, bursa copulatrix; pd, posterior diverticulum; ad, anterior diverticulum; sp, spermatheca; spg, spermathecal gland; mvp, median ventral passage; e8, entapophysis. 